BRD 50566

\title{
Hypoxia-ischemia produces focal disruption of glutamate receptors in developing brain
}

\author{
Faye S. Silverstein ${ }^{1}$, Lynn Torke ${ }^{1}$, John Barks ${ }^{1}$ and Michael V. Johnston ${ }^{1,2}$ \\ ${ }^{\prime}$ Departments of Pediatrics and Neurology, University of Michigan Medical School and ${ }^{2}$ Center for Human Growth and Development, \\ University of Michigan, Ann Arbor, MI (U.S.A.)
}

(Accepted 16 December 1986)

Key words: Perinatal; Hypoxia-ischemia; Autoradiography; Glutamic acid; Dentate gyrus

\begin{abstract}
We examined the impact of a perinatal hypoxic-ischemic insult on the distribution of glutamate receptors in developing brain. We used a well characterized rodent model for perinatal hypoxic-ischemic encephalopathy, unilateral carotid artery occlusion followed by exposure to $8 \%$ oxygen for $2.5 \mathrm{~h}$ in 7-day-old rat pups. This preparation results in focal neuronal damage in striatum, hippocampus, and cortex ipsilateral to ligation. Alterations in the regional distribution of glutamate binding in the first $24 \mathrm{~h}$ after the insult were assessed with quantitative in vitro $\left[{ }^{3} \mathrm{H}\right]$ glutamate autoradiography. In lesioned animals, we found progressive selective reductions in $\left[{ }^{3} \mathrm{H}\right]$ glutamate binding in forebrain ipsilateral to ligation in regions destined for neuronal damage. The earliest and most prominent unilateral reductions in binding were noted in the dentate gyrus of hippocampus ( $-45 \pm 9 \%$, compared with contralateral hemisphere at $24 \mathrm{~h}$ ). Acute reductions in specific glutamate binding appear to be a sensitive marker for hypoxic-ischemic neuronal damage in the immature brain. These observations suggest that neurons bearing glutamate receptors may be particularly susceptible to hypoxic-ischemic injury.
\end{abstract}

\section{INTRODUCTION}

Ischemic brain injury in the neonate is an important cause of chronic neurologic disorders including cerebral palsy, mental retardation and epilepsy. Recent evidence in vivo from mature animals and in vitro support the hypothesis that release of endogenous excitatory amino acid neurotransmitters such as glutamate may contribute to the pathogenesis of hypoxic-ischemic neuronal damage ${ }^{14,21,28}$. The regional distribution of glutamate receptors in areas such as the hippocampus has been found to correspond to microscopic patterns of selective neuronal vulnerability to ischemia and related insults. However, little is known about glutamate's role in the evolution of neuronal injury in the immature brain.

In vitro neurotransmitter receptor autoradiography in brain slices has been used to visualize the distribution of excitatory amino acid receptors in rodent and human brain. In infants, large numbers of glutamate receptors are expressed in basal ganglia, hippocampus and cortex in the perinatal period ${ }^{8}$. In one region, the globus pallidus, the concentration of glutamate receptors in infants far exceeds that in adults. We speculated that if glutamate release contributes to selective neuronal vulnerability from hypoxic-ischemic brain injury at this developmental stage, regions enriched in glutamate receptors might be especially vulnerable to disruption.

To study the neurochemical events evolving acutely after a focal ischemic insult in the immature brain, we used a well characterized immature rodent model for hypoxic ischemic encephalopathy. In 7-day-old rat pups, right carotid artery ligation was followed by exposure to an $8 \%$ oxygen environment for $2.5 \mathrm{~h}$. Hypoxemia combined with unilateral carotid ligation causes progressive ischemia in forebrain ipsilateral to occlusion and results in focal unilateral neuronal

Correspondence: F.S. Silverstein, The University of Michigan, Neuroscience Laboratory Building, 1103 E. Huron, Ann Arbor, MI 48104, U.S.A. 
damage $\mathrm{e}^{10,19,20}$. Striatum, dorsal hippocampus, and overlying cortex are prominently affected. We used in vitro autoradiography with $\left[{ }^{3} \mathrm{H}\right]$ glutamate to examine acute alterations in the regional distribution of glutamate receptors after this hypoxic-ischemic insult.

\section{MATERIALS AND METHODS}

\section{Animal preparation}

In 7-day-old Sprague-Dawley rat pups, the right carotid artery was exposed and ligated under ether anesthetic, as previously described ${ }^{10,20}$. After a 1-h recovery period with the dam, pups were placed in plastic chambers, warmed to $37^{\circ} \mathrm{C}$, and exposed to $8 \%$ oxygen, balance nitrogen for $2.5 \mathrm{~h}$. Pups were then returned to the dam. Lesioned animals and litter mate controls were sacrificed $1,6,12$ or $24 \mathrm{~h}$ after hypoxic exposure.

In the initial description of this preparation ${ }^{20}$, unilateral carotid ligation was followed by $3.5 \mathrm{~h}$ of $8 \%$ oxygen exposure. However, we have found that when ether is used for anesthesia rather than halothane, few pups survive $3.5 \mathrm{~h}$ of $8 \%$ oxygen. Hypoxic exposure of $2.5 \mathrm{~h}$ was used in these experiments to optimize both survival (less than $10 \%$ mortality) and uniformity in the extent of tissue damage.

\section{Autoradiography}

Frozen tissue sections $(20 \mu \mathrm{m})$ were prepared for autoradiography and adjacent sections were Nisslstained to assess histology.

To examine $\left[{ }^{3} \mathrm{H}\right]$ glutamate binding, the methods of Greenamyre et al. ${ }^{7}$ were used. This procedure which assays glutamate binding in the presence of $\mathrm{Ca}^{2+}$ and $\mathrm{Cl}^{-}$has been used to characterize the normal distribution of binding sites in the developing brain and has identified a transient dense perinatal expression of glutamate binding sites in globus pallidum ${ }^{8}$.

In preliminary studies, sections from lesioned animals and controls were incubated with $\left[{ }^{3} \mathrm{H}\right]$ glutamate (22 Ci/mmol, Amersham) for $45 \mathrm{~min}$ at $2{ }^{\circ} \mathrm{C}$. The buffer was $50 \mathrm{mM}$ Tris- $\mathrm{HCl}$ containing $2.5 \mathrm{mM} \mathrm{CaCl}_{2}$ and a range of concentrations of cold glutamate (0.1$1 \mu \mathrm{M})$ were added. Similar regional distributions of binding were observed in this range and for these experiments a single concentration was chosen to assess relative side to side changes $\left(55 \mathrm{nM}, 2.4 \times 10^{6}\right.$ $\mathrm{dpm} / \mathrm{ml}\left[{ }^{3} \mathrm{H}\right]$ glutamate, working specific activity 16 $\mathrm{Ci} / \mathrm{mmol})$. Blanks were prepared by adding excess cold glutamate $(1 \mathrm{mM})$ to the incubation buffer. After the incubation, sections were rinsed sequentially with buffer and then $2.5 \%$ glutaraldehyde in acetone. Dried sections and tritium standards (ARC) were apposed to tritium sensitive Ultrafilm (LKB) in $\mathrm{X}$-ray cassettes. After an 18-day exposure at $4{ }^{\circ} \mathrm{C}$, the film was developed. Autoradiograms were analyzed with a computer assisted densitometer. At least 10 readings from each region were averaged and $\mathrm{dpm} / \mathrm{mg}$ protein was determined by a computer generated polynomial regression analysis which compared film densities produced by the tissue sections with those produced by the radioactive standards ${ }^{17}$. Binding densities were quantitated bilaterally in 14 brain regions: $\mathrm{CA}_{1}, \mathrm{CA}_{3}$ and inferior blade of dentate gyrus of hippocampus; anterior and posterior caudate; anterior and posterior globus pallidum; cingulate cortex; and 6 arbitrarily defined zones of frontoparietal cortex (using the atlas of Paxinos and Wat$\operatorname{son}^{18}$ to identify structures).

At each time point, in each region, side to side differences in binding density were calculated and values in lesioned and control pups were compared with Student's $t$-tests. One way analysis of variance was used to compare the magnitudes of change in 3 regions of the hippocampus analyzed at $24 \mathrm{~h}$ posthypoxia.

\section{RESULTS}

Autoradiograms prepared from normal control 7and 8-day-old rat pups demonstrated symmetrical high densities of specific $\left[{ }^{3} \mathrm{H}\right]$ glutamate binding in striatum, globus pallidum, hippocampus and cortex (Fig. 1) ${ }^{8}$. In lesioned animals, over $24 \mathrm{~h}$ following hypoxia-ischemia we found progressive selective reductions in $\left[{ }^{3} \mathrm{H}\right]$ glutamate binding in forebrain ipsilateral to carotid ligation.

In autoradiograms prepared from animals sacrificed $1 \mathrm{~h}$ after hypoxic exposure, there was little apparent change in the distribution of glutamate binding in the ischemic hemisphere compared with the opposite side and with controls. However, quantitative analysis revealed that glutamate binding was significantly reduced in one region, the dentate gyrus ipsilateral to ligation $(-18 \pm 5 \%, n=7, P<0.01$ com- 

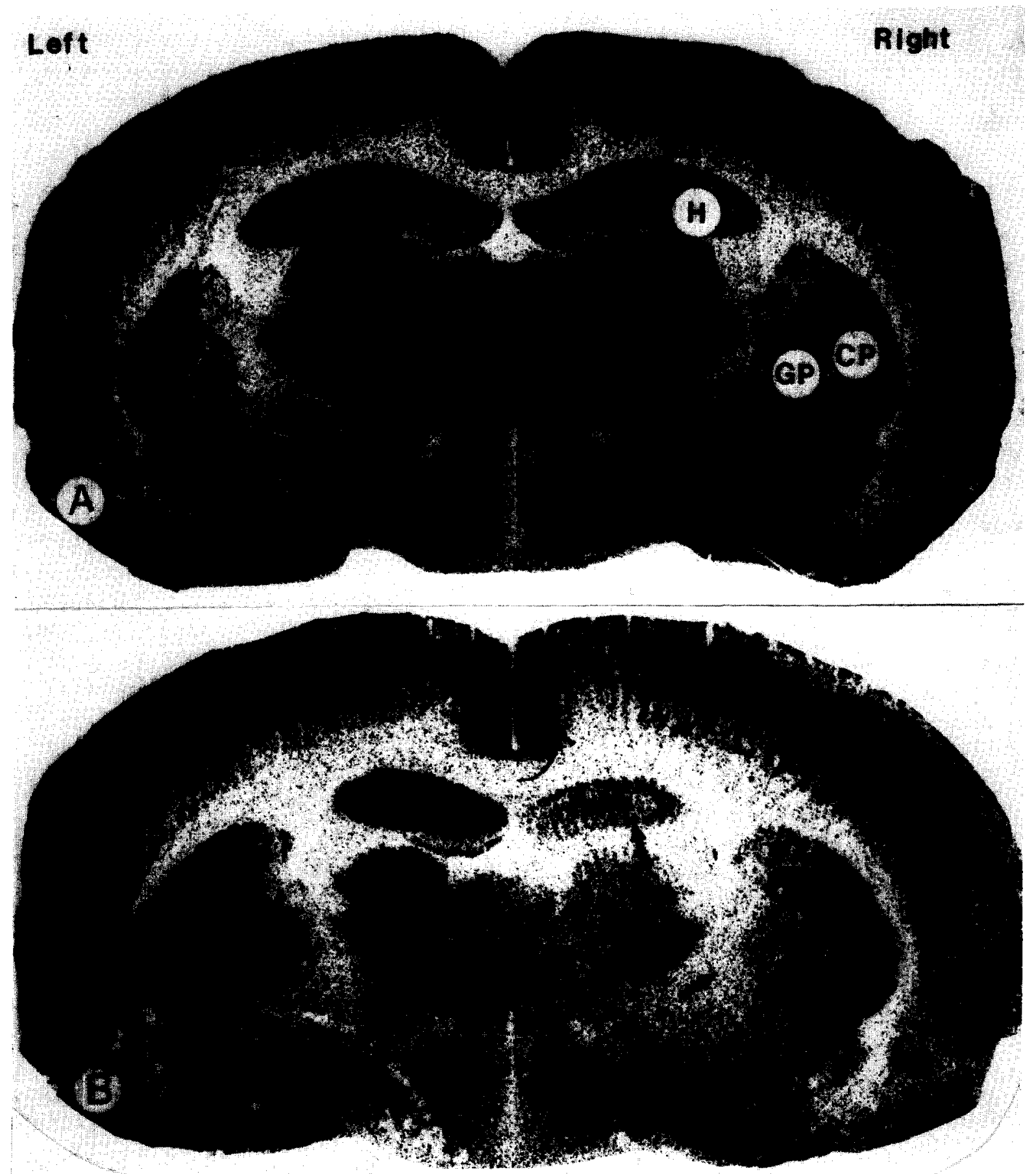

Fig. 1. A: photograph of a $\left[{ }^{3} \mathrm{H}\right]$ glutamate autoradiogram of a coronal brain section from a normal 8-day-old rat pup. B: photograph of a $\left[{ }^{3} \mathrm{H}\right]$ glutamate autoradiogram of coronal brain section from an 8-day-old rat pup, sacrificed $24 \mathrm{~h}$ after right carotid artery ligation followed by $2.5 \mathrm{~h}$ of $8 \%$ oxygen exposure. Frozen sections were incubated with $55 \mathrm{nM}$ glutamate $\left(16 \mathrm{Ci}\left[{ }^{3} \mathrm{H}\right]\right.$ glutamate/mmol) and were then apposed to tritium-sensitive film Ultrafilm (LKB) for 18 days (see Materials and Methods for details of procedure). Darker areas represent regions with higher densities of $\left[{ }^{3} \mathrm{H}\right]$ glutamate binding. Sections representing blanks, incubated with $1 \mathrm{mM}$ glutamate, were included for each brain and could not be readily differentiated from the background of the film. Arrows point to regions where binding density is reduced ipsilateral to ligation. GP, globus pallidum; $\mathrm{CP}$, caudate putamen; $\mathrm{H}$, hippocampus 
pared with the corresponding region of the opposite hemisphere).

At $6-12 \mathrm{~h}$ posthypoxia, more extensive reductions in binding developed ipsilateral to ligation. In the dentate gyrus, at $6 \mathrm{~h}$ posthypoxia $\left[{ }^{3} \mathrm{H}\right]$ glutamate binding was reduced by $28 \pm 8 \%(n=4)$ ipsilateral to ligation and at $12 \mathrm{~h}$ posthypoxia specific binding in the dentate gyrus was reduced by $31 \pm 10 \%(n=4)$. At $24 \mathrm{~h}$ after hypoxia, more widespread, but regionally selective, unilateral reductions in specific binding were apparent in hippocampus, caudate, globus pallidum and cortex (Fig. 1).

Autoradiograms from 15 lesioned animals sacrificed $24 \mathrm{~h}$ after hypoxia were analyzed (Table I). In each brain region, the binding density ipsilateral to ligation was compared with the value in the corresponding region contralaterally. Side to side differences were compared with values in untreated agematched controls $(n=8)$. In controls there were no

\section{TABLE I}

\section{$\left.{ }^{3} \mathrm{H}\right]$ Glutamate binding in hypoxic-ischemic brain}

In 15 eight-day-old animals, studied $24 \mathrm{~h}$ after right carotid artery ligation followed by $2.5 \mathrm{~h}$ of $8 \%$ oxygen, and in 8 untreated controls, dpm/mg protein in both cerebral hemispheres in each anatomical region were calculated with a computer assisted densitometer. In each brain 5 sections/region were examined and in each region $\geqslant 5$ readings were made. $\mathrm{CA}$, cornu ammonis; DG, dentate gyrus. In each region, the ratio between values in the right (hypoxic-ischemic) and left hemispheres for each brain and mean values ( \pm S.E.M.) were calculated.

$$
\Delta \%=1-\text { mean } \frac{\text { Left hemisphere value }(\mathrm{dpm} / \mathrm{mg} \text { protein) }}{\text { Right hemisphere value }(\mathrm{dpm} / \mathrm{mg} \text { protein })}
$$

\begin{tabular}{lll}
\hline Anatomic region & $\begin{array}{l}\Delta \% \text { Ipsilateral } \\
\text { to ligation } \\
(n=15)\end{array}$ & $\begin{array}{l}\text { A\% Left vs right } \\
\text { hemisphere } \\
\text { controls } \\
(n=8)\end{array}$ \\
\hline Hippocampus & $-22 \pm 8^{* *}$ & $-1 \pm 4$ \\
$\mathrm{CA}_{1}$ & $-24 \pm 7^{* *}$ & $8 \pm 5$ \\
$\mathrm{CA}_{3}$ & $-45 \pm 9^{* *}$ & $0 \pm 4$ \\
DG & $-13 \pm 3^{* *}$ & $5 \pm 6$ \\
Caudate & $-12 \pm 3^{*}$ & $5 \pm 3$ \\
Anterior & $-19 \pm 4^{* *}$ & $4 \pm 2$ \\
$\quad$ Posterior & $-11 \pm 3^{* *}$ & $2 \pm 2$ \\
Globus pallidum & $-3 \pm 3$ & $3 \pm 2$ \\
Frontoparietal cortex &
\end{tabular}

${ }^{*} P<0.025,{ }^{* *} P<0.005$, Student's $t$-test used to compare mean values in ligates and controls. ${ }^{* * *}$ Average of readings from 6 areas. side-to-side differences. In hippocampus, the extent of inhibition differed in the 3 anatomical regions examined (Fig. 2). In hippocampal regions $\mathrm{CA}_{1}$ and $\mathrm{CA}_{3}$, binding density was reduced over $20 \%$. Loss of binding was greatest in dentate gyrus $(-45 \pm 9 \%, P$ $<0.01$ ANOVA, comparison of values in $\mathrm{CA}_{1}, \mathrm{CA}_{3}$ and dentate gyrus) the region in which the earliest changes had occurred. In caudate and globus pallidum, ipsilateral binding densities were reduced by $13 \pm 3 \%$ and $19 \pm 4 \%$ respectively. Similar reductions were seen in frontoparietal cortex $(-11 \pm 3 \%)$. In contrast, in cingulate cortex, which is not susceptible to ischemic damage in this preparation, binding density was equal bilaterally.

Examination of Nissl-stained sections revealed acute ischemic cell changes (decreased staining of cytoplasm, pyknosis) and macrophage infiltration limited to forebrain ipsilateral to ligation as has been previously described ${ }^{20}$. There was no apparent loss of brain parenchyma. At $1 \mathrm{~h}$ after hypoxic exposure, mild loss of staining was evident in hippocampus and caudate-putamen. At $24 \mathrm{~h}$ after hypoxia-ischemia, there was marked unilateral loss of staining and macrophage infiltration into hippocampus, caudate, globus pallidum and cortex. In hippocampus, the severity of the lesions was similar in $\mathrm{CA}_{1}, \mathrm{CA}_{3}$ and dentate gyrus.

\section{DISCUSSION}

In the first $24 \mathrm{~h}$ after hypoxic-ischemic brain injury in immature animals, we found progressive, selective reductions in specific $\left[{ }^{3} \mathrm{H}\right]$ glutamate binding in regions destined for irreversible neuronal damage. The dentate gyrus of hippocampus was affected earlier than adjacent areas and changes remained most severe in this area at later times.

The glutamate binding sites labelled by this autoradiographic method are concentrated in dendritic zones corresponding with the projection sites of putative glutamatergic pathways ${ }^{7}$. The reductions in glutamate binding likely reflect changes in the number or functional activity of postsynaptic glutamate receptors on dendrites or neuronal cell bodies. Studies in mature animals have demonstrated that dendrites are selectively damaged after transient cerebral ischemia and this pattern of injury has been attributed to the deleterious effects of excitatory neurotransmitter 


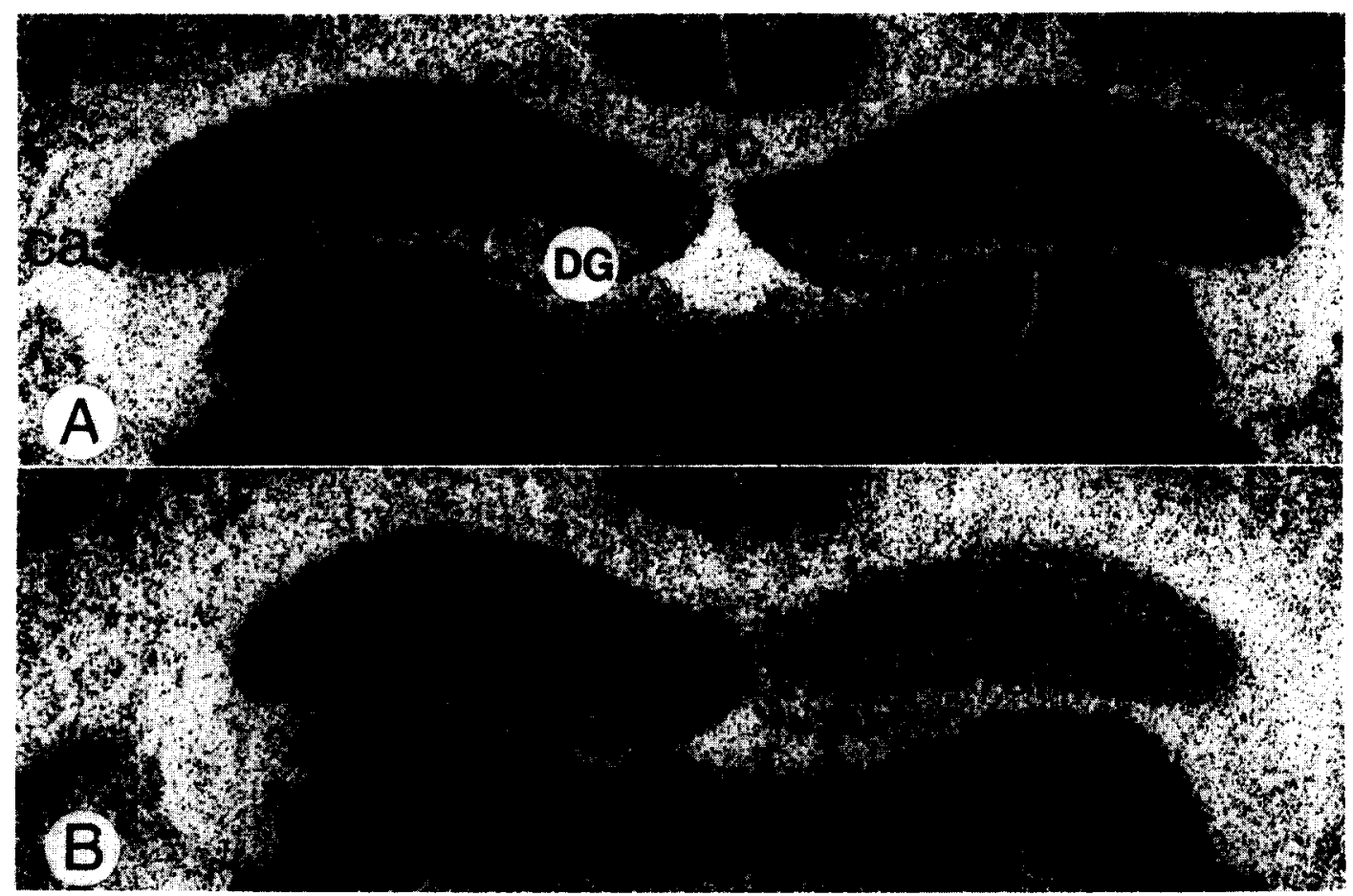

Fig. 2. A: photograph of a $\left[{ }^{3} \mathrm{H}\right]$ glutamate autoradiogram of a coronal brain section from an 8-day-old rat pup at level of dorsal hippocampus (see Materials and Methods for details of autoradiography procedure). ca, cornu ammonis; DG, dentate gyrus; cc, corpus callosum. B: photograph of a $\left[{ }^{3} \mathrm{H}\right]$ glutamate autoradiogram from the corresponding region of an 8-day-old rat pup sacrificed $24 \mathrm{~h}$ after right carotid ligation followed by exposure to $2.5 \mathrm{~h}$ of $8 \%$ oxygen. Decreased $\left[{ }^{3} \mathrm{H}\right]$ glutamate binding in hippocampus ipsilateral to ligation is most evident in the inferior blade of dentate gyrus (arrows), $\mathrm{CA}_{1}$ and $\mathrm{CA}_{3}$.

release.

Histologic evaluation of the brain $24 \mathrm{~h}$ after the hypoxic-ischemic insult revealed that the structural integrity of the tissue was still preserved. However, at this time, there were acute ischemic cell changes in hippocampus, caudate, globus pallidus and cortex, which were similar to the early changes described after transient cerebral ischemia in mature animals ${ }^{9,11,20}$. Thus, the loss of glutamate binding sites could reflect ischemic damage to cell membranes or other acute pathological changes in the ultrastructure of injured neurons.

The apparent reduction in binding density ipsilateral to ligation could conceivably result from focal edema. Rice et al. ${ }^{20}$ found that overall tissue water content increased 1-2\% acutely in the injured cerebral hemisphere. However, both in autoradiograms and in Nissl-stained sections, there was no disruption of lesioned striatum, hippocampus or cortex by interstitial edema $24 \mathrm{~h}$ after the hypoxic-ischemic insult. Thus, it seems unlikely that edema could account for the magnitude of reductions in glutamate binding we observed.

When animals were sacrificed one or two weeks after carotid ligation and hypoxic exposure, we observed atrophy, gliosis and disruption of neuronal organization in Nissl-stained sections in all regions where acute ischemic changes were seen ${ }^{10}$. In hippocampus, both at $24 \mathrm{~h}$ and at 1-2 weeks after the insult, abnormalities were qualitatively similar in $\mathrm{CA}_{1}$, $\mathrm{CA}_{3}$ and dentate gyrus. This pattern differs from the distribution of ischemic injury in mature animals, in which $\mathrm{CA}_{1}$ is much more vulnerable than $\mathrm{CA}_{3}$ and dentate gyrus ${ }^{9,11}$. This pattern of evolution of chronic morphologic damage resembles the distribution of early reductions in glutamate binding we observed suggesting that the autoradiographic pattern reflects progressive ischemic injury to neurons bearing glutamate receptors.

Several factors could influence the regional distribution of acute ischemic injury or the magnitude of inhibition of glutamate binding. For example, variations in cellular energy requirements or ATP levels could contribute to differential susceptibility to hy- 
poxia-ischemia and thereby account for the regional differences in extent of inhibition of binding. Welsh et al. examined regional levels of high energy and glycolytic intermediates during and after hypoxiaischemia in the immature rat brain ${ }^{27}$. ATP levels were markedly depleted in the ischemic hemisphere during hypoxia, and there was a regionally heterogeneous recovery of levels in the first $12 \mathrm{~h}$. In areas where ATP levels remained low there was a corresponding focal depression of NADH fluorescence; this reduction, however, was considerably more prominent in cortex than in hippocampus or caudate and was thus unlikely to account for the alterations in receptor distribution we observed.

The pattern of cell damage, which coincided well with the distribution of glutamate receptors, raised the issue of whether release of endogenous glutamate could produce cell injury in this setting. The neurotoxic properties of excitatory amino acid analogues have been confirmed in many studies in mature animals ${ }^{5}$. Intracerebral injections of the glutamate agonists kainic acid and ibotenate both produce axon-sparing lesions in striatum and hippocampus. Although injection of glutamate produces little damage, probably because of efficient neuronal and glial re-uptake ${ }^{12}$, chronic glutamate infusion elicits similar patterns of morphologic damage ${ }^{13}$.

Reports that intrastriatal injection of kainic acid, a potent neurotoxin in mature animals, did not cause neuronal damage in 7-day-old rat pups suggested that the immature brain was resistant to excitatory amino acid induced neurotoxicity ${ }^{2}$. However, Steiner et al. found that intracerebral injection of ibotenate, an $\mathrm{N}$ methyl-D-aspartate preferring glutamate agonist, caused neuronal degeneration in 7-day-old rat pups $^{26}$. Recently we found as well that intracerebral injections of the glutamate agonist quisqualic acid produced neuronal necrosis in striatum and hippocampus of 7 -day-old animals ${ }^{24}$. These observations suggest that endogenous glutamate could potentially be neurotoxic at this developmental stage.

In mature animals, microdialysis studies have shown that hippocampal extracellular fluid glutamate levels rise markedly during ischemia ${ }^{1}$. It has been postulated that these high levels reflect stimulation of glutamate release in ischemic neurons. Glutamate release has not been measured directly after carotid ligation and hypoxic exposure in 7-day-old rat pups. However, we have found that neuronal glutamate re-uptake is markedly impaired and this factor could contribute to toxic accumulation of glutamate in the synaptic cleft ${ }^{23}$.

In vitro studies have suggested several mechanisms by which glutamate causes damage to the postsynaptic dendrite: enhanced chloride influx with resulting osmotic damage, increased calcium influx with disruption of intracellular metabolism or receptor-mediated stimulation of inositol phosphate hydrolysis $^{16,25}$. Independent of specific receptor-mediated events, ischemia initiates a cascade of biochemical reactions that may lead to cell death ${ }^{19}$. Membrane phospholipid degradation, free radical generation, and intracellular calcium accumulation contribute to disruption of intracellular metabolism. Neurons bearing glutamate receptors may be especially vulnerable because of glutamate-stimulated ionic shifts and inositol phospholipid hydrolysis ${ }^{16,25}$. Degradation of cell membrane phospholipids could readily inhibit the functional activity of membranebound receptors and result in the loss of specific binding we observed ${ }^{15}$.

An alternative interpretation for the reduction in glutamate binding is that it represents a transient pharmacologic response of glutamate receptors in response to increased stimulation by agonist. If hypoxia-ischemia initiates massive glutamate release, loss of binding could reflect receptor 'down-regulation'. The early and more pronounced changes in dentate gyrus could result from increased activity of the glutamatergic input from enterorhinal cortex. Although the dentate is immature, synapses are present by day 5 (ref. 4). However, $\mathrm{CA}_{1}$ which is most vulnerable to ischemic injury in mature animals may receive less stimulation at this age because excitatory pathways from dentate to $\mathrm{CA}_{1}$ are not fully established.

In ligates, focal electrographic seizures develop in the first $12 \mathrm{~h}$ after hypoxia ${ }^{3}$. In mature animals, seizures produce down-regulation of muscarinic receptors in the dentate gyrus and this response is attributed to depolarization rather than excessive agonist release $^{6}$. A similar regulatory mechanism could result in the prominent reduction in glutamate binding in this region.

The early progressive reductions in glutamate binding appear to be a sensitive marker for neuron containing regions which are injured by ischemia. 
Further studies will be required to determine if loss of binding results from a reduction in the number of glutamate receptors or alterations in the affinity of these receptors for glutamate and to examine the temporal relationship between loss of glutamate binding and irreversible neuronal damage.

Such alterations in receptor distribution or function as a consequence of ischemic brain injury may have particular significance in infancy. The most ac-

\section{REFERENCES}

1 Benveniste, H., Drejer, J., Schousboe, A. and Diemer, N., Elevation of the extracellular concentrations of glutamate and aspartate in rat hippocampus during transient cerebral ischemia monitored by intracerebral microdialysis, $J$. Neurochem., 43 (1984) 1369-1374.

2 Campochiaro, P. and Coyle, J., Ontogenetic development of kainate neurotoxicity: correlates with glutamatergic innervation, Proc. Natl. Acad. Sci. U.S.A., 75 (1978) 2925-2929.

3 Chen, R., Silverstein, F.S., Aldridge, W. and Johnston, M.V., Evolution of acute cortical electroencephalogram changes in experimental perinatal hypoxic-ischemic encephalopathy (Abstract), Neurology, Suppl. 1, 36 (1986) 86.

4 Cowan, W.M., Stanfield, B.B. and Kishi, K., The development of the dentate gyrus. In R.K. Hunt (Ed.), Current Topics in Developmental Biology 15: Neural Development, Part 1: Emergence of Specificity in Neural Histogenesis, Academic, New York, 1980, pp. 103-157.

5 Coyle, J.T., Bird, S.J., Evans, R.H., Gulley, R.L., Nadler, J.V., Nicklas, W.J. and Olney, J.W., Excitatory amino acid neurotoxins: selectivity, specificity and mechanism of action, Neurosci. Res. Prog. Bull., 19 (1981) 329-427.

6 Dasheiff, R.M., Savage, D.D. and McNamara, J.O., Seizures down-regulate muscarinic cholinergic receptors in hippocampal formation, Brain Res., 235 (1982) 327-334.

7 Greenamyre, J.T., Young, A.B. and Penney, J.B., Quantitative autoradiographic distribution of $\mathrm{L}-\left[{ }^{3} \mathrm{H}\right]$ glutamate binding sites in rat central nervous system, J. Neurosci., 4 (1984) 2133-2144.

8 Greenamyre, J.T., Penney, J.B., Young, A.B., Hudson, C., Silverstein, F. and Johnston, M.V., Evidence for transient peri-natal glutamatergic innervation of globus pallidus, $J$. Neurosci., in press.

9 Johansen, F.F., Jorgensen, M.B., Von Lubitz, D.K. and Diemer, N.H., Selective dendritic damage in hippocampal $\mathrm{CA}_{1}$ stratum radiatum with unchanged axon ultrastructure and glutamate uptake after transient cerebral ischemia in the rat, Brain Res., 291 (1984) 373-377.

10 Johnston, M.V., Neurotransmitter alterations in a model of perinatal, hypoxic-ischemic brain injury, Ann. Neurol., 13 (1983) 511-518.

11 Kirino, T., Delayed neuronal death in the gerbil hippocampus following ischemia, Brain Res., 239 (1982) 57-69.

12 Kohler, C. and Schwarcz, R., Monosodium glutamate: increased neurotoxicity after removal of neuronal re-uptake sites, Brain Res., 211 (1981) 485-491.

13 McBean, G.J. and Roberts, P.J., Chronic infusion of L-glutamate causes neurotoxicity in rat striatum, Brain Res., 290 (1984) 372-375. tive phase of receptor development occurs in early postnatal life. When a hypoxic-ischemic insult occurs during this critical period, the orderly progression of receptor organization and synapse formation will be disrupted. Use of in vitro autoradiography to map receptor activity during the recovery period after perinatal injury will likely prove to be a useful approach for examining plasticity and re-organization in the developing nervous system.

14 Meldrum, B., Excitatory amino acids and anoxic ischemic brain damage, Trends Neurosci., 88 (1985) 47-48.

15 Muakkahssah-Kelley, S.F., Anderson, J.W., Shih, J.C. and Hochstein, P., Decreased ${ }^{3} \mathrm{H}$-serotonin and ${ }^{3} \mathrm{H}$-spiperone binding consequent to lipid peroxidation in rat cortical membranes, Biochem. Biophys. Res. Commun., 104 (1982) 1003-1010.

16 Olney, J.W., Price, M.P., Samson, L. and Labruyere, J., The role of specific ions in glutamate neurotoxicity, Neurosci. Lett., 65 (1986) 65-71.

17 Pan, H.S., Frey, K.A., Young, A.B. and Penney, J.B., Changes in ${ }^{3} \mathrm{H}$-muscimol binding in substantia nigra, entopeduncular nucleus, globus pallidus, and thalamus after striatal lesions as demonstrated by quantitative receptor autoradiography, J. Neurosci., 3 (1983) 1189-1198.

18 Paxinos, G. and Watson, C., The Rat Brain in Stereotaxic Co-ordinates, Academic, Sydney, 1982.

19 Raichle, M., The pathophysiology of brain ischemia, Ann. Neurol., 13 (1983) 2-10.

20 Rice, J.E., Vanucci, R.C. and Brierley, J.B., The influence of immaturity on hypoxic ischemic brain damage in the rat, Ann. Neurol., 9 (1981) 131-141.

21 Rothman, S. and Olney, J., Glutamate and the pathophysiology of hypoxic-ischemic brain damage, Ann. Neurol., 19 (1986) 105-111.

22 Silverstein, F.S., Buchanan, K. and Johnston, M.V., Pathogenesis of hypoxic-ischemic brain injury in a perinatal rodent model, Neurosci. Lett., 49 (1984) 271-278.

23 Silverstein, F.S., Buchanan, K. and Johnston, M.V., Hypoxia-ischemia disrupts striatal high affinity ${ }^{3} \mathrm{H}$-glutamate uptake into synaptosomes, J. Neurochem., 47 (1986) 1614-1619.

24 Silverstein, F.S., Chen, R. and Johnston, M.V., The glutamate analogue quisqualic acid is neurotoxic in striatum and hippocampus of immature rat brain, Neurosci. Lett., 71 (1986) 13-18.

25 Sladeczek, F., Pin, J.P., Recasens, M., Bockaert, J. and Weiss, S., Glutamate stimulates inositol phosphate formation in striatal neurons, Nature (London), 317 (1985) 717-719.

26 Steiner, H.X., McBean, G.J., Kohler, C., Roberts, P.J. and Schwarcz, R., Ibotenate-induced neuronal degeneration in immature rat brain, Brain Res., 307 (1984) 117-124.

27 Welsh, F.A., Vannucci, R.C. and Brierley, J.B., Columnar alterations of NADH fluorescence during hypoxia-ischemia in immature rat brain, J. Cereb. Blood Flow Metab., 2 (1982) 221-228.

28 Wieloch, T., Lindvall, O., Blomquist, P. and Gage, F.H., Evidence for amelioration of ischemic neuronal damage in the hippocampal formation by lesions of the perforant path, Neurol. Res., 7 (1985) 24-26. 